\title{
Complicaciones quirúrgicas post-trasplante renal. Estudio en 185 casos
}

\author{
D.A. Pérez Fentes, M. Blanco Parra, V. Toucedo Caamaño, R. Romero Burgos, \\ J.A. Puñal Rodríguez, E. Varo Pérez \\ Unidad de Trasplante Abdominal. Hospital Clínico Universitario de Santiago de Compostela. \\ Santiago de Compostela. \\ Actas Urol Esp 2005; 29 (6): 578-586
}

\section{RESUMEN}

COMPLICACIONES QUIRÚRGICAS POST-TRASPLANTE RENAL. ESTUDIO EN 185 CASOS

Objetivo: Análisis de incidencia, diagnóstico y tratamiento de complicaciones quirúrgicas en el trasplante renal.

Método: Estudio retrospectivo de la incidencia de complicaciones quirúrgicas en 185 trasplantes renales únicos, revisando su diagnóstico y tratamiento.

Resultados: En 185 trasplantes se producen un 27\% de complicaciones quirúrgicas. Sólo un paciente perdió el injerto secundario a éstas y su mortalidad asociada fue nula. Tiempo medio de isquemia fría 20 horas. Utilización de catéter doble J (19\%), a criterio del cirujano. Complicaciones vasculares 3,2\% (todas estenosis de arteria renal). Complicaciones urológicas 6,4\% (en similar porcentaje estenosis y fístulas). Hematomas perirrenales 7\%. Linfoceles 4,9\%. Complicaciones peritoneales 4\%. Otras 4\%. Diagnóstico clínico-radiológico en la mayoría de los casos. Requirieron intervención (endo-radiológica o quirúrgica) el 14\%, individualizada según el caso.

Conclusiones: Nuestros resultados no difieren de los de otras grandes series publicadas. La implicación de un único equipo de cirujanos manteniendo la misma técnica vascular y de ureteroneocistostomía parece influir en nuestra baja incidencia de complicaciones. La ecografía-doppler abdominal sistemática como control en los primeros días post-trasplante contribuye al diagnóstico de las complicaciones quirúrgicas. El tratamiento inicial de elección, salvo excepciones, es endoscópico-conservador.

Palabras clave: Trasplante renal. Complicaciones quirúrgicas. Diagnóstico. Tratamiento.

\section{ABSTRACT}

\section{SURGICAL COMPLICATIONS AFTER KIDNEY TRASPLANTATION. RESEARCH BASED ON 185 CASES}

Objective: To analyze the incidence of surgical complications its diagnosis and treatment after renal transplantation.

Methods: A retrospective study measuring the incidence of surgical complications and reviewing its diagnosis and treatment in 185 renal single transplants.

Results: 185 transplants, 27\% had surgical complications. Only one patient lost the graft due to surgical complications and there was no associated mortality. Cold ischemia time 20 hours. Double $\mathrm{J}$ stenting in 19\%, under surgeon's opinion. Vascular complications 3,2\% (all of them renal artery stenosis). Urological complications 6,4\%. Perinephric haematoma 7\%. Lymphocele 4,9\%. Peritoneum related complications $4 \%$. Other $4 \%$. The diagnosis was clinical and radiological in most of cases. $14 \%$ needed any kind of intervention.

Conclusions: Our results are similar to those reported in other recent series. Only one surgical team involved and the same technique for vascular and vesico-ureteric anastomosis probably makes lower our complications rate. Early postoperative abdominal ultrasonography contributes to the diagnosis of surgical complications. The initial treatment approach is the endoscopic-conservative one, with exceptions. 
$\mathrm{D}^{2}$ esde 1933 (año en el que Voronoy realizó el primer trasplante renal en humanos) hasta nuestros días, el trasplante renal ha sufrido grandes avances, tanto en el ámbito médico (nuevos inmunosupresores, control sistemático de infecciones oportunistas, mayor precisión en el análisis de compatibilidad inmunológica...) como en el quirúrgico (progresos en la técnica, optimización de riñones subóptimos...).

Los cirujanos de trasplante renal podemos contribuir a mejorar la técnica mediante el análisis de nuestros resultados y la comparación con los de otros grupos. El objetivo de este estudio es analizar la incidencia de complicaciones quirúrgicas y su tratamiento en nuestro centro, para intentar corregir aquellos aspectos negativos en los que podemos influir, obteniendo así una menor tasa de complicaciones y un mayor éxito en el tratamiento de las mismas.

\section{PACIENTES Y MÉTODOS}

De septiembre de 1997 a diciembre de 2003 se realizaron 192 trasplantes renales en la Unidad de Trasplante Abdominal del Hospital Clínico Universitario de Santiago de Compostela. De esta serie excluiremos un trasplante de donante vivo, 3 trasplantes páncreas-riñón y 3 dobles (uno de ellos en la misma fosa ilíaca), por lo que el número definitivo de pacientes a estudio es 185 .

La edad media de los donantes fue 45 años (intervalo de 14 a 77 años), tratándose el 58,4\% de varones y el $41,6 \%$ de mujeres. En cuanto a los receptores, la edad media fue de 47 años (intervalo de 15 a 68 años), con similar distribución en cuanto a sexo. La procedencia de los mismos fue: $72 \%$ hemodiálisis, $19 \%$ diálisis peritoneal y $9 \%$ pre-hemodiálisis. El $76 \%$ de los órganos procedian de extracciones locales. El seguimiento medio de los pacientes fue 47,5 meses (mínimo de 10 meses).

En cuanto a la inmunosupresión, realizamos inducción con triple terapia: Anticalcineurinios (inicialmente Ciclosporina A en el primer 35\% de casos en la serie y posteriormente Tacrolimus (65\%)) asociados con Glucocorticoides (preferentemente Metilprednisolona) y Mofetil micofenolato. Reservamos los Anticuerpos monoclonales (Basiliximab o Daclizumab) para pacientes de alto riesgo inmunológico o para prevención de necro- sis tubular aguda en pacientes con factores de riesgo. Previo al inicio de la intervención el receptor recibe profilaxis antibiótica con Cefoxitina, que se continúa en el postoperatorio inicial.

Realizamos un estudio retrospectivo de la incidencia de complicaciones quirúrgicas en la serie, revisando su diagnóstico y los resultados del tratamiento empleado para resolver las mismas.

\section{TÉCNICA QUIRÚRGICA}

Cirugía de banco

Colocamos el injerto sobre la mesa de trabajo. Bajo hipotermia realizamos revisión sistemática del parénquima renal y de su pedículo vascular. En nuestra serie encontramos 19\% de anomalías arteriales, $5 \%$ de venosas y una única anomalía ureteral.

Eliminamos el exceso de grasa perirrenal, sin excesivo celo a nivel periureteral y con preservación de la misma en el "triángulo de Belzer" con la finalidad evitar la lesión de posibles arterias polares inferiores, con el consiguiente daño a la vascularización ureteral.

Preparación de las anastomosis vasculares. En caso de anomalías arteriales, intentamos anastomosar arterias de similar calibre y próximas entre si "en cañón de escopeta" siempre y cuando no tengan parche aórtico, pues preferimos crear un parche único o anastomosarlas por separado. Si las arterias son de calibres distintos, se anastomosa la fina sobre la gruesa en término-lateral. En casos de vena renal derecha corta elongamos la misma utilizando vena cava. Para estas reparaciones utilizamos sutura monofilamento irreabsorbible 6/0.

Perfusión del injerto con solución de Wisconsin (200-300 cc), mediante cánula fina a través de arteria renal, con especial cuidado de no traumatizar su intima.

\section{Técnica}

Colocamos al paciente en decúbito supino. Repleccionamos la vejiga con 250-300 cc de povidona iodada diluida en suero en proporción 3:500 mediante sonda vesical bajo condiciones de asepsia, con la finalidad de identificar fácilmente la vejiga durante el tiempo de anastomosis uretero-vesical y evitar contratiempos ${ }^{1}$. El trasplante fue heterotópico en ambas fosas ilíacas 
mediante abordaje extraperitoneal, utilizando preferentemente riñones derechos en fosa ilíaca derecha e izquierdos en fosa ilíaca izquierda. En terceros y cuartos trasplantes se utilizó la vía transperitoneal. Todas las intervenciones fueron realizadas por un equipo de 3 cirujanos.

Realizamos una incisión oblícua desde $2 \mathrm{~cm}$ por encima de la espina ilíaca anterosuperior hasta la sínfisis púbica, seccionando músculos oblicuos mayor y menor y músculo transverso, teniendo especial cuidado a nivel de los vasos epigástricos, ligándolos en la mayoría de los casos. Sección del ligamento redondo en mujeres y movilización del cordón espermático en varones. Desplazamos el peritoneo hacia craneal y línea media mediante disección roma. Exposición de vasos ilíacos, con la mínima disección del tejido linfático y adiposo perivascular posible. En este momento colocamos el órgano sobre el lecho quirúrgico envuelto en un sistema de creación propia que nos permite suspenderlo sobre el campo con relativa hipotermia. Según las características anatómicas de donante y receptor elegimos la sutura vascular por la que comenzar (arterial o venosa).

En nuestra serie, salvo algunos casos, las anastomosis fueron sobre arteria y vena ilíacas externas. En la sutura arterial excluimos la arteria ilíaca externa de la circulación mediante clamps de ilíaca y realizamos arteriotomía previa elección del lugar idóneo de anastomosis mediante inspección manual del mismo, evitando las posibles zonas de ateromatosis. Lavado del interior con suero heparinizado. Sutura vascular continua con material monofilamento irreabsorbible de $5 / 0$ en ambas caras. Previo a finalizar la sutura, nuevo lavado en el interior con suero heparinizado. Una vez terminada, colocamos una pinza tipo bulldog en arteria renal retirando los clamps, de este modo comprobamos la estanqueidad de la sutura. La anastomosis venosa la realizamos sobre vena ilíaca externa, excluyéndola mediante pinza de Satinsky, suturando con material de 6/0 y colocando pinza de bulldog sobre vena renal una vez finalizada. Desclampaje de vena y arteria renales, en este orden. Comprobamos la adecuada perfusión del injerto e identificamos las posibles zonas de hemorragia, realizando hemostasia de las mismas. Las suturas vasculares procuramos realizarlas sin movilizar el riñón.
Anastomosis urétero-vesical. Identificamos la vejiga gracias a la distensión de la misma previamente con suero y povidona iodada. En los 185 casos de la serie realizamos ureteroneocistostomía mediante técnica extravesical tipo LichGregoir (no requiriendo en ningún caso otra técnica). Mínima miotomía del detrusor con bisturí eléctrico e incisión en mucosa vesical con tijera fina. Espatulamos uréter distal previa sección del exceso de uréter y realizamos tres caras de sutura continua independiente con material reabsorbible 4/0 o 5/0. Posteriormente se sutura el detrusor sobre la anastomosis mediante puntos sueltos, actuando así de mecanismo antirreflujo. En 35 ocasiones tutorizamos mediante catéter ureteral tipo doble $\mathrm{J}(16 \mathrm{~cm} / 6 \mathrm{Fr})$ con la finalidad de proteger la anastomosis, en casos de: uréter mal vascularizado, donante añoso, receptor menor de 15 años, excesivo tiempo de isquemia fría, vejiga subóptima... Lavado del lecho quirúrgico con anfotericina B. Dejamos drenaje cutáneo cerrado de tipo aspirativo que retiramos cuando las salidas son menores de 50 cc en 24 horas y sonda vesical durante 5-7 días. El catéter ureteral, en los casos en los que se utilizó se retiró entre la $4^{\underline{a}}$ y la $6^{\underline{a}}$ semana.

\section{RESULTADOS}

En los 185 trasplantes renales de la serie, se produjeron 50 complicaciones quirúrgicas en 46 receptores (27\%). Dentro de éstas, 26 fueron complicaciones mayores (las que requirieron algún tipo de intervención, bien sea quirúrgica o endo-radiológica) y 24 complicaciones menores (las que no necesitaron ningún tipo de intervención). Debido a las complicaciones quirúrgicas hubo sólo una pérdida de injerto (múltiples estenosis arteriales intrarrenales con fracaso de la angioplastia) y la mortalidad asociada a las mismas fue nula. El tiempo medio de isquemia fría fue de 20,21 horas (intervalo 10-29) Tabla 1.

\section{COMPLICACIONES VASCULARES}

Constituyen el 3,2\% de la serie y en su totalidad fueron estenosis de la arteria renal. Todas fueron diagnosticadas mediante arteriografía, en el contexto clínico de hipertensión arterial refractaria post-trasplante o deterioro de la función renal. La localización de la misma fue en 5 casos 
Tabla 1

Tipo de complicaciones

\begin{tabular}{lcc}
\hline Tipo & Número & Porcentaje \\
\hline Complicaciones & & \\
Quirúrgicas Totales & $\mathbf{5 0}$ & $\mathbf{2 7}$ \\
$\quad$ Compl. Mayores & 26 & 14 \\
Compl. Menores & 24 & 13 \\
Compl. Vasculares & $\mathbf{6}$ & $\mathbf{3 , 2}$ \\
$\quad$ Estenosis arterial & 6 & 3,2 \\
Compl. Urológicas & $\mathbf{1 2}$ & $\mathbf{6 , 4}$ \\
$\quad$ Estenosis/Obstrucción & 6 & 3,2 \\
$\quad$ Fístula & 6 & 3,2 \\
Colecciones líquidas & $\mathbf{2 2}$ & $\mathbf{1 1 , 9}$ \\
$\quad$ Hematoma & 13 & 7 \\
Linfocele & 9 & 4,9 \\
Compl. Peritoneales & $\mathbf{4}$ & $\mathbf{2 , 2}$ \\
Otras & $\mathbf{3}$ & $\mathbf{1 , 6}$ \\
\hline
\end{tabular}

post-anastomótica y en el caso restante fueron estenosis múltiples intrarrenales. La edad media de los donantes en los trasplantes que tuvieron estenosis arterial fue 37,5 años, inferior a la del resto de pacientes (44,7 años). La edad media de los receptores fue también inferior en el grupo con estenosis arterial (41 años) frente a los 47 años del grupo control. En relación con el sexo de los receptores, encontramos estenosis arteriales en 3 de 108 hombres $(2,7 \%)$ y en 3 de 77 mujeres $(3,9 \%)$. En todos los casos se intentó angioplastia transluminal percutánea (ATP), con éxito en nuestro centro en 4 pacientes. Un caso fracasó en nuestro hospital, resultando exitosa la ATP en otro centro. El último caso, en el que había múltiples estenosis intrarrenales, provocó la pérdida de injerto en el primer mes, recibiendo un segundo trasplante posteriormente. En nuestra serie no aparecen casos de trombosis arteriales, trombosis venosas, aneurismas o pseudoaneurismas, infección ni dehiscencia de sutura.

\section{COMPLICACIONES UROLÓGICAS}

Incidencia del $6,4 \%$ dividida en porcentajes similares en estenosis/obstrucción ureteral y fístulas. Tutorización ureteral mediante catéter doble $\mathrm{J}$ en el $19 \%$ de casos.

\section{Estenosis/Obstrucción}

Constituyen el 3,2\% del total de casos. Se sospechó la misma ante el deterioro de la función renal en los 6 pacientes, en los que la ecografía abdominal mostraba distintos grados de dilatación de la vía urinaria. En todos ellos se realizó nefrostomía y pielografía anterógrada. La localización de la obstrucción fue en 2 casos en la unión urétero-vesical y en los otros 4 a nivel de uréter distal. Momento de aparición entre $8^{\mathrm{a}} \mathrm{y}$ $20^{\text {a }}$ semana. Las edades medias de donante y receptor fueron de 47 y 46 años respectivamente en el grupo con estenosis urinaria frente a los 44 y 47 años del grupo sin estenosis. Tres de 108 varones $(2,7 \%)$ presentaron estenosis ureteral frente a 3 casos que aparecieron en 77 mujeres (3,9\%). En 1 caso no se requirió dilatación de la región estenótica, en 2 pacientes la obstrucción se solucionó con dilatación posterior a la nefrostomía y en los tres restantes se requirió cirugía (2 con reimplantación de uréter a vejiga y uno con resección del segmento estenótico y anastomosis uréter-uréter término-terminal.

\section{Fistula Urinaria}

Constituyen también el 3,2\% del total de pacientes trasplantados. Sospechamos esta complicación en los 6 pacientes tras deterioro de la función renal, oliguria y fiebre con ocasional drenaje a través de la herida quirúrgica de líquido que tras analizarse, resultó ser orina. En todos los casos la ecografía abdominal mostraba una colección líquida no conocida previamente. Realizamos nefrostomía y pielografía anterógrada para localizar la región fistulosa: en 5 casos se localizó a nivel urétero-vesical y el otro se trató de una fístula piélica. En cuanto al momento de aparición, 5 casos debutaron antes del primer mes y el último al segundo mes post- trasplante (la fístula piélica). La edad media del donante fue mayor en el paciente con fístula (54,3 años) que en el paciente sin fístula (44,2 años). La edad media del receptor en el grupo con fístula fue de 54,8 años frente a los 46,9 años del grupo sin fístula. 4 de 108 varones $(2,2 \%)$ presentaron fístula urinaria frente a un $1,1 \%$ de mujeres ( 2 mujeres de 77). Un caso se resolvió espontáneamente y en los otros cinco se requirió intervención quirúrgica: 3 reimplantaciones de uréter donante a nativo tras resección de área necrótica, 1 vejiga psoica y 1 corrección de fístula piélica mediante cierre quirúrgico y cateterización. 


\section{COLECCIONES LÍGUIDAS}

Constituyen el 11,9\% de la serie, tratándose el $7 \%$ de hematomas perirrenales y el $4,9 \%$ de linfoceles.

\section{Hematoma perirrenal}

En nuestra serie aparecen 13 pacientes que presentaron ecográficamente en el post-operatorio una colección líquida a nivel perirrenal compatible con hematoma. La edad media de donante y receptor en el grupo con hematoma perirrenal fue de 44,3 y 49,1 años respectivamente frente a los 44,6 y 47 años del grupo control. Siete de los 108 varones $(3,8 \%)$ presentaron hematoma perirrenal frente a 6 de 77 mujeres $(3,2 \%)$. En cuanto a su tratamiento, en dos ocasiones se requirió tratamiento quirúrgico evacuador, uno en las primeras 24 horas post-trasplante tras presentar shock hipovolémico. Los otros 11 pacientes fueron tratados de forma conservadora.

\section{Linfocele}

La incidencia de linfocele en nuestro grupo es de un 4,9\%. El diagnóstico fue ecográfico en todos los casos. En el grupo de pacientes que presentaron linfocele, la edad media del donante fue de 51,7 años y la del receptor de 49,1 años. En el grupo de pacientes sin linfocele estas edades fueron de 44,2 y 47 años respectivamente. Cinco de los 108 varones de la serie $(2,7 \%)$ presentaron linfocele frente a 4 de 77 mujeres $(2,2 \%)$. En 5 pacientes el linfocele se resolvió espontáneamente. En los otros cuatros se requirió punción del mismo y escleroterapia con povidona iodada, resultando uno de ellos en intervención quirúrgica urgente tras puncionar por error la vena ilíaca produciéndose un gran hematoma retroperitoneal con shock hipovolémico.

\section{COMPLICACIONES PERITONEALES}

Suponen el 2,2\% del total. En un caso se trató de un ileo reflejo severo que se resolvió espontáneamente sin ningún tipo de intervención. Otro paciente presentó una peritonitis fecaloidea secundaria a perforación colónica que requirió intervención quirúrgica. Los dos casos restantes se trataron de hemoperitoneo, resueltos ambos quirúrgicamente.

\section{OTRAS COMPLICACIONES}

Suponen el 1,6\% del total de casos. En dos pacientes se produjo dehiscencia de la sutura parietal y el tercero presentó hematuria macroscópica. Todos se resolvieron sin necesidad de tratamiento quirúrgico o endo-radiológico.

\section{DISCUSIÓN}

Nuestra tasa global de complicaciones quirúrgicas es de un $27 \%$, en el hemos incluido tanto las que requirieron algún tipo de intervención (14\%) como las que no lo necesitaron (13\%). La tasa global de complicaciones quirúrgicas publicada recientemente por otros grupos oscila entre el 5 y el 20\%. ${ }^{2,3}$ Esta enorme variabilidad se debe a que no existe un consenso en la clasificación de estas complicaciones ni una definición común de los criterios que permiten encuadrar a un paciente en el concepto de "complicación quirúrgica", provocando su infra o sobreestimación. Se hace, por tanto, necesario acordar unos criterios comunes sobre este punto para todas las unidades que nos dedicamos al trasplante renal.

\section{COMPLICACIONES VASCULARES}

Nuestra tasa de complicaciones vasculares $(3,2 \%)$ coincide con las publicadas por otros grupos. $^{2,3}$ En general se aceptan porcentajes de complicación vascular inferiores al 5\%. Las complicaciones vasculares arteriales son más frecuentes que las venosas. Nuestros pacientes con complicación vascular fueron casos de estenosis arteriales.

La estenosis de la arteria renal puede ser debida a múltiples factores: traumatismos durante la extracción de órganos, lesiones en el trabajo de banco o durante el propio implante. El diagnóstico es inicialmente de sospecha: deterioro inexplicado de la función renal, aparición de hipertensión arterial refractaria...Varias pruebas de imagen no-invasivas pueden utilizarse (Eco-doppler, angio-TC, angio-RM) pero su confirmación definitiva debe hacerse con arteriografía. En algunos centros experimentados utilizan Eco-doppler con sustancias de contraste, con resultados bastante certeros. La implicación de una estenosis de arteria renal en el desarrollo de una hipertensión puede descartarse con un renograma con Captopril. 
En nuestra serie todos los casos fueron sospechados tras la aparición de hipertensión arterial refractaria y confirmados mediante arteriografía, la que además nos informó sobre la localización de dicha estenosis. Según su localización éstas pueden clasificarse en: estenosis de la línea de sutura, estenosis post-anastomóticas o estenosis múltiples en el lecho arterial distal, con aproximaciones terapéuticas distintas. En general, la primera opción terapéutica es la angioplastia transluminal percutánea (ATP). Optamos inicialmente por la colocación de un stent descubierto en las estenosis del ostium, las obstrucciones, las disecciones o cuando la ATP resulta insuficiente. De nuestros pacientes, 5 presentaron estenosis post-anastomóticas resueltas con éxito tras ATP y un paciente presentó múltiples estenosis de lecho arterial distal, refractarias a ATP que determinaron la pérdida del injerto. Para este tipo de pacientes algunos autores proponen el autotrasplante renal simple o asociado a cirugía de banco reparadora-sustitutiva ${ }^{4-7}$.

\section{COMPLICACIONES UROLÓGICAS}

La incidencia de complicaciones urológicas publicadas en otras series oscila ente el 2 y el $20 \%{ }^{2,3,7,8-10}$ influyendo en esta variabilidad que algunos grupos incluyen en este capítulo a las infecciones de tracto urinario ${ }^{9}$. Nuestro $6,4 \%$ se divide en similar porcentaje entre fístulas y estenosis ureterales, no incluyendo por tanto las infecciones y no habiéndose registrado casos de litiasis ni reflujo.

Algunos estudios publicados profundizan en los posibles factores etiológicos de las complicaciones urológicas ${ }^{11,12}$ pero la mayoría de ellas parecen el resultado de errores técnicos en la obtención o implantación del riñón ${ }^{13}$ o de un fracaso en la curación de los tejidos (secundario a isquemia, inflamación, inmunosupresión, rechazo, estado nutricional del receptor...). En algunas series se describen casos de obstrucción de causa extrínseca (linfoceles, hematomas...). En general parece aceptado que durante la extracción y el trabajo de banco la disección periureteral y del hilio renal no debe ser excesiva con la finalidad de no dañar la vasculatura ureteral. En cuanto al implante ureteral, actualmente la mayoría de los grupos realizan ureteroneocistos- tomía mediante técnica extravesical, permitiendo utilizar menor longitud de uréter, que presumiblemente estará mejor vascularizado y con menor posibilidad de angulación o torsión. Nosotros realizamos la técnica extravesical tipo Lich-Gregoir, si bien bastantes series recientes realizan la de Taguchi con muy buenos resultados, aunque con una mayor incidencia de hematuria ${ }^{14}$. Algunos autores proponen la utilización sistemática de catéter doble J para la prevención de dichas complicaciones, pero esta cuestión es controvertida ${ }^{15-17}$. En nuestra serie cateterizamos un 19\% de uréteres, basándonos en el criterio del cirujano (uréter mal vascularizado, donante añoso, receptor menor de 15 años, excesivo tiempo de isquemia fría, vejiga subóptima...). La no aleatorización del empleo de ésta técnica en dos grupos similares de pacientes no nos permite concluir si su utilización disminuye la incidencia de complicación urológica en nuestra serie.

\section{Estenosis ureteral}

La sospecha clinica de este cuadro es un deterioro de la función renal acompañado de oligoanuria que puede aparecer en el postoperatorio inmediato (frecuentemente secundario a defectos en el reimplante uréterovesical) requiriendo diagnóstico diferencial con el rechazo agudo, la necrosis tubular aguda, nefrotoxicidad por inmunosupresores y patología vascular. Sin embargo, su momento de aparición más frecuente es en torno al primer año, asociadas en su mayoría con rechazo crónico. En nuestra serie el momento de aparición fue entre la $8^{\mathrm{a}}$ y $20^{\mathrm{a}}$ semanas. La principal prueba diagnóstica es la ecografía abdominal, mostrando dilatación de la vía urinaria del injerto, pudiendo también realizarse un renograma diurético. Es recomendable hacer una ecografía en los primeros días post-trasplante a todos los pacientes, que nos sirva como referencia ante la aparición de futuras complicaciones. La presencia de una dilatación pielo-calicial moderada es un hallazgo común en riñones trasplantados. Sólo si ésta progresa o si es moderada-severa, junto con los datos clínicos del enfermo podremos diagnosticar obstrucción ureteral. La actitud de elección es la realización de una nefrostomía percutánea, que recuperará de forma rápida la función renal y el estado general 
del paciente. La realización de una pielografía anterógrada puede permitirnos la localización del lugar de la estenosis, en su mayoría en el tercio distal de uréter o en la unión urétero-vesical, en lo que coinciden nuestros seis pacientes. Las técnicas percutáneas son actualmente de elección para corregir las estenosis de vía, quedando el tratamiento quirúrgico en un segundo escalón. ${ }^{19,20,21}$ En nuestra serie dos casos se corrigieron mediante dilatación con balón y posterior colocación de catéter doble J. En general, las técnicas percutáneas tienen grandes ventajas por la utilización de anestesia local, fácil acceso anatómico y mínimo número de complicaciones. Además permiten mejorar las condiciones del enfermo como puente a la cirugía en el caso de que no resulten definitivas. Cuatro pacientes con estenosis ureteral requirieron tratamiento quirúrgico, habiéndose publicado numerosas técnicas para la corrección de esta complicación ${ }^{22}$.

\section{Fistula ureteral}

La sospecha de fístula ureteral se produce en las primeras semanas post-trasplante en pacientes con deterioro de la función renal, fiebre, fuga a través de la herida quirúrgica y/o sepsis. Las fístulas de aparición precoz generalmente son de origen técnico o isquémico, pudiendo también aparecer en etapas tardías, asociadas a rechazo. Cinco de nuestros casos se presentaron en el primer mes y el sexto en el segundo. Es recomendable analizar la concentración de creatinina e iones del líquido fugado para determinar si puede corresponder a orina. Al igual que en las estenosis, la prueba de imagen inicial de elección es una ecografía abdominal, que mostrará la presencia de una colección líquida peri-injerto no existente en la ecografía previa de control. El diagnóstico de certeza se produce tras la realización de nefrostomía percutánea y pielografía anterógrada, que nos mostará el lugar de la fístula, mayoritariamente la unión urétero-vesical, en lo que todas las grandes series coinciden. ${ }^{19,20,21}$ En nuestro caso, 5 de los 6 pacientes presentaron fístula a nivel urétero-vesical y el sexto a nivel piélico. La colocación vía anterógrada de un catéter ureteral tipo doble $J$ es el tratamiento inicial de elección, optándose por tratamiento quirúrgico ante fístulas grandes o fracaso del tratamiento endoscópico conservador ${ }^{22}$. En nuestro caso, de los 6 pacientes con fístula sólo uno se resolvió con tratamiento endoscópico, requiriendo los otros cinco actitud quirúrgica abierta. La técnica dependerá del lugar de la fuga (nueva ureteroneocistostomía, ureteroureterostomía tras resección del segmento fistuloso, ureteropielostomía, colgajo de Boari, etc).

\section{COLECCIONES LÍQUIDAS}

\section{Hematoma perirrenal}

$\mathrm{El}$ diagnóstico de hematoma perirrenal es fundamentalmente ecográfico, tras documentar la existencia de una colección líquida no existente en la ecografía inicial de control. Suele ser secundario a alteraciones adquiridas en la coagulación del paciente (por la anticoagulación post-operatoria o por la coagulopatía de su insuficiencia renal crónica) o a una deficiente hemostasia durante el acto quirúrgico. El tratamiento de elección es conservador, como se refleja en nuestra serie, reservando medidas más agresivas para hematomas que provoquen intensa afectación del paciente o deterioro de la función renal.

\section{Linfocele}

La incidencia media de linfoceles publicada por otros grupos oscila ente el 0,5 y el $20 \% .{ }^{23}$ Es una de las complicaciones quirúrgicas más frecuentes post-trasplante renal. En nuestro centro se detectaron un $4,9 \%$ de linfoceles, tras la realización sistemática de ecografía.

El origen del linfocele suele ser una excesiva disección de los vasos ilíacos, lesionando los abundantes vasos linfáticos que los recubren o un deficiente sellado de los linfáticos del hilio renal del donante. En nuestro centro realizamos una cuidada disección de los vasos iliacos, así como ligadura con material reabsorbible de aquellos linfáticos lesionados (tanto en el trabajo de banco como en el implante) susceptibles de producir linfocele. La actitud suele ser conservadora en la mayoría de los casos, salvo en linfoceles grandes, que provoquen uropatía obstructiva o repercusión clínica en el trasplantado, en cuyo caso realizamos una punción evacuadora e instilación de agentes esclerosantes en su cavidad (povidona iodada). Algunos autores proponen la instilación del sellador de fibrina. ${ }^{24,25}$ Cuando se 
produce el fracaso de este tratamiento, una alternativa quirúrgica es la marsupialización intraperitoneal. Ninguno de nuestros casos requirió actitud quirúrgica; pese a ello se intervino a un paciente por una complicación vascular relacionada con una punción de intención esclerosante.

\section{CONCLUSIONES}

1. La incidencia de complicaciones quirúrgicas totales en nuestra serie fue de un $27 \%$, requiriendo intervención (quirúrgica o endo-radiológica) un $14 \%$, a las que denominaremos complicaciones mayores.

2. Existe una gran variabilidad en los datos de incidencia publicados. Se hace necesario llegar a un acuerdo común en la definición de complicación quirúrgica post-trasplante renal y en su clasificación para poder así establecer comparaciones. Los resultados, sin embargo, en cuanto a la incidencia de complicaciones quirúrgicas totales o divididas en categorías (vasculares, urológicas, colecciones líquidas, peritoneales y otras) no difieren de los de las otras grandes series publicadas: nuestra incidencia de complicaciones urológicas $(6,4 \%)$ está en el límite inferior de lo publicado por otras series (2-20\%).

3. La realización del trasplante por un único equipo de cirujanos manteniendo la misma técnica vascular y de ureteroneocistostomía (extravesical tipo Lich-Gregoir) parece influir en esta baja incidencia de complicaciones.

4. No podemos concluír que la colocación de catéter doble $\mathrm{J}$ disminuye la incidencia de complicación urológica debido a la falta de homogeneidad entre el grupo de pacientes en los que se le colocó y en el que no se hizo, ya que esto fue a criterio del cirujano.

5. La ecografía-doppler abdominal sistemática de control en los primeros días post-trasplante contribuye de forma significativa al diagnóstico de la mayoría de las complicaciones quirúrgicas.

6. Las medidas endo-radiológicas constituyen el primer escalón terapéutico de las complicaciones post-trasplante, reservando el tratamiento quirúrgico para casos seleccionados o refractarios a ellas. También contribuyen al diagnóstico y a mejorar el estado del paciente previo a cirugía.

\section{REFERENCIAS}

1. Blanco Parra M, Calviño J, Romero Burgos $R$ et al. Implantación ureteral en peritoneo. Una complicación excepcional en el trasplante renal. Actas Urol Esp 2002;26 (8):579-580.

2. García de Jalón A, Pascual Regueiro D, Trívez Boned MA, et al. Trasplante Renal. Técnica y complicaciones. Actas Urol Esp 2003;27(9):662-677.

3. Beyga ZT, Kahan BD. Surgical complications of kidney transplantation. Journal of Nephrology 1998;11(3):137-145.

4. Bruno S, Remuzzi G, Ruggenenti P. Transplant renal artery stenosis. J Am Soc Nephrol 15(1):134-141.

5. Serrallach Milá N, Franco Miranda E, Riera Canals LI, et al. Patologia vásculo-renal. Actas Urol Esp 2002;26(9):600- 616.

6. Guzman-Rodriguez JH, Plata Muñoz JJ, Mancilla E, et al. Renal artery stenosis after transplantation: treatment using percutaneous transluminal angioplasty and placement of an expandible metal luminar prótesis. Rev Invest Clin 2003;55(3):297-304.

7. Bruno S, Ferrari S, Remuzzi G, Ruggenenti P. Doppler Ultrasonography in posttransplant renal artery stenosis: a reliable tool for assessing effectiveness of revascularization? Transplantation 2003;76(1):147-153.

8. Guardiola Mas A, Sánchez Gascón F, Gimeno L, et al. Complicaciones urológicas en el trasplante renal. Estudio en 250 casos. Actas Urol Esp 2001;25(9):628-636.

9. Butterworth PC, Horsburgh T, Veitch PS, Bell PRF, Nicholson ML. Urological complications in renal transplantation: impact of a change of technique. Br J Urol 1997;79: 499-502.

10. Shoskes DA, Hanbury D, Cranston D, Morris PJ. Urological complications in 1.000 consecutive renal transplant recipients. J Urol 1995;153:18-21.

11. Reek C, Noster M, Burmeister D, Wolff JM, Seiter H. Urological complications of renal transplantation: a series of 900 cases. Transplant Proc 2003;35:2106-2107.

12. Streeter EH, Little DM, Cranston DW, Morris PJ. Complicaciones urológicas del trasplante renal: una serie de 1.535 pacientes. BJU Int 2002;90:627-634.

13. Agüera L, Robles JE, Rosell D. Análisis multivariado de los factores influyentes en la aparición de las complicaciones quirúrgicas en el trasplante renal. Actas Urol Esp 1994;18 (2):117-123.

14. Tzimas Gn, Hayati H, Tchervenkov JI, Metrakos PP. Ureteral implantation technique and urologic complications in adult kidney transplantation. Transplant Proc 2003;35: 2420-2422.

15. Secin FP, Rovegno AR, Marrugat EJ, Virasoro R, Lautersztein GA, Fernández H. Comparing Taguchi and LichGregoir ureterovesical reimplantation techniques for kidney transplants. J Urol 2002;168:926-930.

16. Briones Mardones G, Burgos Revilla FJ, Pascual Santos J et al. Estudio comparativo entre anastomosis ureteral con o sin cateterización con doble $J$ en trasplante renal. Actas Urol Esp 2001;25(7):499-503.

17. Dominguez J, Clase CM, Mahalati K, et al. Is routine ureteric stenting needed in kidney transplantation? A randomized trial. Transplantation 2000;70(4):597-601.

18. Derouich A, Hajri M, Pacha K, Ben Hassine L, Chebil M, Ayed M. Impact de l'utilisation de la sonde JJ lors de la transplantation rénale sur l'incidence des complications urologiques et de l'infection urinaire. Prog Urol 2002;12: 1209-1212. 
19. Calahorra Fernández FJ, Parra Escobar JL, Rodríguez Antolín A, et al. Tratamiento percutáneo de las complicaciones en el trasplante renal. Actas Urol Esp 1989;13(3): 161-166.

20. Crespo Martínez L, Fernández Fernández E, Burgos Revilla $\mathrm{J}$, et al. Tratamiento de la fístula y la estenosis urinaria compleja en el trasplante renal. Arch Esp de Urol 1996;49 (2): 149-153.

21. Pourmand G, Mehrsai AR, Taheri M. Evaluation of endourological interventions used to treat urological complications in 394 kidney recipients. Transplant Proc 2000;32: 524-525.

22. Król R, Cierpka L, Ziaja J, Pawlicki J, Budzinski G. Sur gically treated early complications after kidney transplantation. Transplant Proc 2003;35:2241-2242.

23. Atray NK, Moore F, Zaman F, Caldito G, et al. Post transplant lymphocele: a single centre experience. Clin Transplant 2004;18(Suppl 12):46-49.
24. Chin A, Ragavendra N, Hilborne L, Gritsch HA. Fibrin sealant sclerotherapy for treatment of lymphoceles following renal transplantation. J Urol 2003;170:380-383.

25. Romero Otero J, Rodríguez Antolín A, Sanchís Bonet A, et al: Tratamiento de linfoceles posttrasplante renal con sellador de fibrina: experiencia inicial. Actas Urol Esp 2004;27(5): 183.

Dr. D.A. Pérez Fentes

Servicio de Urología

Hospital Clínico Univ. de Santiago de Compostela

Travesía Choupana, $\mathrm{s} / \mathrm{n}$

15706 Santiago de Compostela (A Coruña)

e-mail: danielfentes@yahoo.es

(Trabajo recibido el 4 noviembre 2004) 